\title{
Management of postpartum iron deficiency anemia: review of literature
}

\author{
Mohamed Saber ${ }^{1}$, Mohamed Khalaf ${ }^{2}$, Ahmed M. Abbas ${ }^{2 *}$, Sayed A. Abdullah ${ }^{2}$
}

${ }^{1}$ Department of Obstetrics and Gynecology, Aswan University Hospital, Aswan, Egypt
${ }^{2}$ Department of Obstetrics and Gynecology, Faculty of Medicine, Assiut University, Assiut, Egypt

Received: 03 November 2018

Accepted: 06 December 2018

\section{*Correspondence:}

Dr. Ahmed M. Abbas,

E-mail: bmr90@hotmail.com

Copyright: ( ) the author(s), publisher and licensee Medip Academy. This is an open-access article distributed under the terms of the Creative Commons Attribution Non-Commercial License, which permits unrestricted non-commercial use, distribution, and reproduction in any medium, provided the original work is properly cited.

\begin{abstract}
Anemia is a condition in which either the number of circulating red blood cells or their hemoglobin concentration is decreased. As a result, there is decreased transport of oxygen from the lungs to peripheral tissues. The standard approach to treatment of postpartum iron deficiency anemia is oral iron supplementation, with blood transfusion reserved for more server or symptomatic cases. There are a number of hazards of allogenic blood transfusion including transfusion of the wrong blood, infection, anaphylaxis and lung injury, any of which will be devastating for a young mother. These hazards, together with the national shortage of blood products, mean that transfusion should be viewed as a last resort in otherwise young and healthy women. Currently, there are many iron preparations available containing different types of iron salts, including ferrous sulfate, ferrous fumarate, ferrous ascorbate but common adverse drug reactions found with these preparations are mainly gastrointestinal intolerance like nausea, vomiting, constipation, diarrhoea, abdominal pain, while ferrous bis-glycinate (fully reacted chelated amino acid form of iron) rarely make complication. Two types of intravenous (IV) preparations available are IV iron sucrose and IV ferric carboxymaltose. IV iron sucrose is safe, effective and economical. Reported incidence of adverse reactions with IV iron sucrose is less as compared to older iron preparations (Iron dextran, iron sorbitol), but it requires multiple doses and prolonged infusion time. Intramuscular iron sucrose complex is particularly contraindicated because of poor absorption. It was also stated that when iron dextran is given intravenously up to $30 \%$ of patients suffer from adverse effects which include arthritis, fever, urticaria and anaphylaxis.
\end{abstract}

Keywords: Iron deficiency, Intravenous iron, Oral iron, Postpartum anemia

\section{INTRODUCTION}

Postpartum iron deficiency anemia is a major public health problem. In the United States, approximately $13 \%$ of women 0-6 months postpartum are iron deficient and $10 \%$ are anemic. ${ }^{1}$ Low-income postpartum women in the United States are disproportionately affected by these health outcomes: $22 \%$ are anemic, $30 \%$ are iron deficient, and $10 \%$ are iron deficient and anemic

WHO report on anemia in pregnancy estimates that, $43 \%$ of non-pregnant women of reproductive age in developing countries, and $12 \%$ in industrialized countries, are anemic; these estimates rise to $56 \%$ and $18 \%$, respectively, by the third trimester of pregnancy. ${ }^{2}$ After childbirth, $\mathrm{Hb}$ levels fall slightly during the first 24 hours because of blood loss and then rise over the next 2 to 5 days. $\mathrm{Hb}$ should return to the normal non-pregnant range by 7 days.

In Western countries, the most common cause of anemia during pregnancy and the postpartum period is iron deficiency. Daily iron demand increases nearly 10 folds from the start of pregnancy to term. ${ }^{3}$ However, less than 
$25 \%$ of women start their pregnancies with iron stores sufficient to meet requirements, and only 5\% increase their iron intake sufficiently during pregnancy to make up that difference. ${ }^{3}$

Postpartum anemia is more common and lasts longer in poor women than in those who are better- off: between 4 and 26 weeks after giving birth, roughly one in four lowincome women suffer from anemia; the proportion reaches nearly half, however, among those who were anemic during pregnancy and among black women. These findings, based on data for women enrolled in a federally sponsored nutrition program in 12 states, suggest a sharply higher prevalence of anemia among low-income women than has been found elsewhere among their better-off counterparts. They also indicate that although women's iron levels (which drop during pregnancy) typically recover 4-6 weeks after delivery, low-income women remain at risk of suffering from anemia for a substantially longer period. ${ }^{1}$

\section{Etiology and risk factors}

The postpartum anemia risk factors supported by CDC involves three equally weighted risk markers:

- Third trimester anemia.

- Excessive blood loss during delivery.

- Multiple births.

There are three risk markers of postpartum anemia not included in the CDC criteria:

- Multiparity.

- $\quad$ Pre-pregnancy obesity.

- Not exclusively breastfeeding.

\section{PATHOGENESIS OF IRON DEFICIENCY ANEMIA}

Iron deficiency anemia may be classified into 3 stages: storage iron deficiency, iron deficient erythropoiesis, and iron deficiency anemia. Initially, iron body stores are preferentially utilized for accelerated erythropoiesis. After depletion of body iron stores, erythropoiesis and production of other iron-containing proteins (such as myoglobin) become limited, leading to an overt iron deficiency anemia. ${ }^{4}$

Anemia is exacerbated as iron-deficient erythrocytes have a shortened survival due to their fragility, which accelerates reticuloendothelial cell sequestration and destruction. The observed erythrocyte morphologic changes with the underlying iron deficiency reflect the severely hampered hemoglobin synthesis and are characterized by hypochromasia and microcytosis. ${ }^{5}$

Furthermore, the hemoglobin-deficient erythroid precursors are thought to undergo additional mitoses while attempting to achieve ideal cytoplasmic hemoglobin levels, thereby exaggerating the microcytosis. ${ }^{6}$

\section{DIAGNOSIS OF IRON DEFICIENCY ANEMIA}

Anemia is defined as a decrease concentration of $\mathrm{Hb}$ in the blood, cutoff depending on age and gender, but isolated $\mathrm{Hb}$ measurement has both low specificity and low sensitivity. The latter can be improved by including measures of iron deficient erythropoiesis. ${ }^{7}$

The biomarkers of hypochromia provide information about the iron supply and are reliable markers of iron restricted erythropoiesis in complex clinical situations. An appropriate combination of laboratory tests gives evidence of iron depletion, reflects iron restricted red cells production, and so will help to establish a correct assessment of the iron status and thus the appropriate treatment. $^{8}$

The WHO defines anemia as blood hemoglobin values of less than $7.7 \mathrm{mmol} / \mathrm{l}(13 \mathrm{~g} / \mathrm{dl})$ in men and $7.4 \mathrm{mmol} / \mathrm{l}(12$ $\mathrm{g} / \mathrm{dl}$ ) in women. Typically, the evaluation of the cause of anemia includes a complete blood cell count, peripheral smear, reticulocyte count, and serum iron indices. The severity of anemia is based on the patient's hemoglobin/hematocrit level. ${ }^{9}$

Iron deficiency anemia is characterized by microcytic, hypochromic erythrocytes and low iron stores. The mean corpuscular volume is the measure of the average red blood cell volume and mean corpuscular hemoglobin concentration is the measure of the concentration of hemoglobin in a given volume of packed red blood cells.

The normal references ranges for mean corpuscular volume is $80-100 \mathrm{fL}$ and mean corpuscular hemoglobin concentration is $320-360 \mathrm{~g} / \mathrm{l}$. The patient's cells are said to be microcytic and hypochromic, respectively, when these values are less than the normal reference range. Of note, up to $40 \%$ of patients with true iron deficiency anemia will have normocytic erythrocytes (i.e. a normal mean corpuscular volume does not rule out iron deficiency anemia). ${ }^{10}$

Iron studies diagnostic for iron deficiency anemia consist of a low hemoglobin $(<7.7 \mathrm{mmol} / \mathrm{l}$ in men and $7.4 \mathrm{mmol} / \mathrm{l}$ in women), a low serum iron $(<7.1 \mathrm{mg} / \mathrm{l})$, a low serum ferritin (storage form of iron) $(<30 \mathrm{ng} / \mathrm{l})$, a low transferrin saturation $(<15 \%)$, and a high total iron-binding capacity $(>13.1 \mathrm{mmol} / \mathrm{l}){ }^{11}$

The ferritin level may be misleading in the presence of acute or chronic inflammation as ferritin is also an acute phase reactant and thus one cannot exclude iron deficiency as the cause of anemia when the serum ferritin is normal or even elevated in the presence of an inflammatory process. ${ }^{10}$ In the presence of an underlying infection or inflammation other iron markers may be useful including the reticulocyte hemoglobin content 
which, because reticulocytes are only 1-2 days old, is reflective of the iron available in the bone marrow for erythropoiesis. ${ }^{12}$

\section{TREATMENT OF IRON DEFICIENCY ANEMIA}

\section{Oral iron}

Iron has been used to treat anemia for more than 300 years. Oral iron therapy is the most widely prescribed treatment for iron deficiency anemia, however, there are many issues that may prevent oral iron supplementation from successfully managing iron deficiency anemia. For instance, many patients do not respond adequately to oral iron therapy due to difficulties associated with ingestion of the tablets and their side effects.

Side effects may play a significant role in rates of compliance. ${ }^{13}$ Furthermore, the presence of bowel disease may affect the absorption of iron and thereby minimize the benefit received from oral iron therapy. ${ }^{14}$ Oral iron supplements are desirable as first-line therapy as they are safe, cheap, and effective in restoring iron balance. ${ }^{9}$

\section{Side effects}

The side effects of oral iron therapy include gastrointestinal disturbances characterized by colicky pain, nausea, vomiting, diarrhea, and/or constipation, and occur in about $50 \%$ of patients taking iron preparations. ${ }^{14}$ Furthermore; the most widely prescribed oral iron is mainly composed of ferrous salts. ${ }^{13}$

Ferrous salts are characterized by low and variable absorption rates. Its absorption can be limited by ingestion of certain foods as well as mucosal luminal damage. Therefore, ferric compounds were introduced to avoid such obstacles. However, these compounds are generally less soluble and have poor bioavailability.

\section{Intravenous iron}

Oral iron is a less than ideal treatment, however, with gastrointestinal toxicity occurring in $35 \%$ to $59 \%$ of patients, and a long course needed to resolve anemia and replenish stores. ${ }^{15}$ Non-adherence to a prescribed course of oral iron is common, and even in adherent patients, poor intestinal absorption fails to compensate for iron need in the presence of ongoing blood losses. ${ }^{16}$

While intravenous (IV) iron has the capability of bypassing all these issues, there remain concerns about the acute safety profiles of the available products and the potential for long-term harm from repeated iron administration. Although any IV iron can cause acute severe reactions, the incidence and severity of reactions are less than may be appreciated by physicians and the doses commonly administered in clinical practice are insufficient to result in parenchymal organ injury. ${ }^{17}$

\section{Iron products}

\section{High molecular weight iron dextran}

Several publications have cited safety concerns with this preparation. During a brief period in 1997, when LMW ID became unavailable, HMW ID was the only formulation available. During this period, spontaneous reports to the FDA of AEs from IV iron increased 11fold. Numerous publications warned against the use of HMW ID. ${ }^{18}$ The National Comprehensive Cancer Network and the nursing journal of the American Society of Nephrology proscribed its use. It has been removed from the formularies of all Veterans' Administration hospitals in the United States and its protectorates and is not available in Europe. Despite this, some hospital pharmacists continue to view all iron dextran products as equals and many physicians lack awareness of the differences between the two iron dextrans. ${ }^{19}$

Mamula and associates published their experience with total dose infusion (TDI) in children with inflammatory bowel disease and reported a 9-fold increase in the incidence of AEs with HMW ID, compared with LMWID. ${ }^{20}$ In a review of suspected iron dextran AEs, Fletes and colleagues noted that AEs were 8.1 times more likely to occur with HMW ID, and concluded that serious AEs related to IV iron dextran were rare and appeared to depend on the specific formulation of IV iron dextran. ${ }^{21}$

\section{Low molecular weight iron dextran}

Given the current state of knowledge, this is the preferred formulation of iron dextran. Unlike the iron salts, FG and IS, this formulation can be administered as an IV bolus or TDI. Eschbach and colleagues were the first to show the benefit of iron dextran in augmenting the response to erythropoietin in patients with the anemia of chronic kidney disease (CKD) undergoing dialysis. ${ }^{22}$ Subsequently, it has been shown that marked reductions in ESA dosage could be achieved with the addition of iron dextran. ${ }^{23}$

\section{Ferric gluconate}

Following its approval for use in hemodialysis patients in 2002, FG (and later IS) rapidly replaced iron dextran as the preferred IV iron preparation. Millions of doses have been given, with AEs being almost exclusively minor infusion reactions. Although AEs have been reported with all IV irons, AEs with this formulation, when high doses are avoided, are rare. ${ }^{24}$

FG administration has been shown to reduce ESA requirements in hemodialysis patients with elevated ferritin levels, to improve anemia without ESAs in irondeficient patients with CKD and to correct anemia in dialysis patients with high serum ferritin and low transferrin saturations. ${ }^{25,26}$ 


\section{Iron sucrose}

By far, the largest experience in the published literature is with this formulation. Aronoff and associates showed the safety of replacement and maintenance regimens of IS in hemodialysis patients. ${ }^{27}$ In a randomized, controlled trial comparing IV IS to oral iron in anemic patients with nondialysis dependent CKD, Van Wyck and colleagues showed that IS, given as $1000 \mathrm{mg}$ in divided doses, was more effective than oral iron. ${ }^{28}$

IS can be safely administered as a 2-minute bolus or as a short infusion in doses up to $300 \mathrm{mg}$, but higher doses have been proscribed. ${ }^{29}$ When higher doses are administered, even with infusions lasting 2 hours, hypotension, nausea, and low back pain are observed.

\section{Ferric carboxymaltose}

This formulation of IV iron was the first of the new agents to be approved for more rapid administration of large doses. FC can be administered as an infusion of $500-1500 \mathrm{mg}$ in 15 minutes; however, only doses up to $1000 \mathrm{mg}$ are currently approved. No test dose is required. Anker and colleagues published their experience with $200 \mathrm{mg}$ boluses of FC in patients with left ventricular ejection fractions of $45 \%$ or less. ${ }^{30}$ They concluded that treatment with IV FC in patients with chronic heart failure and iron deficiency, with or without anemia, improves symptoms, functional capacity, and quality of life with an acceptable side-effect profile.

\section{Ferumoxytol}

This formulation was approved by the FDA in June 2009 for iron replacement in patients with IDA and CKD. No test dose is required. This product is unique in that it can be administered as a relatively large dose $(510 \mathrm{mg}$, exclusive vial size) in $<20$ seconds. There is no data on higher doses. The published safety profile is consistent with that of LMW ID, FG, and IS. ${ }^{17}$

In a crossover study on patients with IDA and CKD not on dialysis, $510 \mathrm{mg}$ of ferumoxytol or placebo was administered in 17 seconds twice in 1 week to 711 patients or placebo to 713. One significant $\mathrm{AE}$ (anaphylaxis) was observed in the treatment arm in a patient with a history of multiple drug allergies. The authors concluded that ferumoxytol is well tolerated and has a safety profile similar to placebo in anemic patients with CKD. ${ }^{31}$

\section{Iron isomaltoside}

This formulation is the newest of the three agents able to provide large doses of IV iron more rapidly than iron dextran. Iron Isomaltoside (II) is approved for administration in doses up to $20 \mathrm{mg} / \mathrm{kg} .{ }^{32}$
In a cohort of 182 patients with anemia of CKD who received 584 injections given as a 100 - to $200-\mathrm{mg}$ bolus or TDI in doses ranging from 462 to $1800 \mathrm{mg}$ in 30 to 60 minutes, no serious AEs were observed, and efficacy was consistent with established guidelines for CKD. As with $\mathrm{FC}$, no test dose is required. II contains strongly bound iron that enables a controlled and slow release of bioavailable iron to iron-binding proteins with minimal free iron release. ${ }^{32}$

\section{Funding: No funding sources}

Conflict of interest: None declared

Ethical approval: The study was approved by the Institutional Ethics Committee

\section{REFERENCES}

1. Bodnar LM, Cogswell ME, Scanlon KS. Low income postpartum women are at risk of iron deficiency. J Nutr. 2002;132(8):2298-302.

2. World Health Organization (WHO) (1992): The Prevalence of Anaemia in Women: a tabulation of available information, Division of Family Health, Maternal Health and Safe Motherhood Programme, Division of Health Protection and Promotion, Nutrition Programme; WHO, $2^{\text {nd }}$ ed. World Health Organization, Geneva, Switzerland.

3. Milman N, Bergholt T, Eriksen L, Byg KE, Graudal $\mathrm{N}$, Pedersen $\mathrm{P}$, et al. Iron prophylaxis during pregnancy-how much iron is needed? A randomized dose-response study of $20-80 \mathrm{mg}$ ferrous iron daily in pregnant women. Acta Obstet Gynecol Scand. 2005;84(3):238-47.

4. Khalafallah A, Dennis A, Bates J, Bates G, Robertson IK, Smith L, et al. A prospective randomized, controlled trial of intravenous versus oral iron for moderate iron deficiency anaemia of pregnancy. J Int Med. 2010;268(3):286-95.

5. Anderson C, Aronson I, Jacobs P. Erythrocyte deformability is reduced and fragility increased by iron deficiency. Hematol. 1999;4(5):457-60.

6. Naigamwalla D, Webb J and Giger U. Iron deficiency anemia. Can Vet J. 2012;53:250-6.

7. Weiss G. Iron metabolism in the anemia of chronic disease. Biochimica Biophysica Acta (BBA)-General Subjects. 2009;1790(7):682-93.

8. Katodritou E, Zervas K, Terpos E, Brugnara C. Use of erythropoiesis stimulating agents and intravenous iron for cancer and treatment-related anaemia: the need for predictors and indicators of effectiveness has not abated. Brit J Haematol. 2008;142(1):3-10.

9. Johnson-Wimbley TD, Graham DY. Diagnosis and management of iron deficiency anemia in the $21 \mathrm{st}$ century. Ther Adv Gastroenterol. 2011;4(3):177-84.

10. Bermejo F, García-López S. A guide to diagnosis of iron deficiency and iron deficiency anemia in digestive diseases. World J Gastroenterol: WJG. 2009;15(37):4638-43. 
11. Clark S. Iron deficiency anemia: Diagnosis and management. Curr Opin Gastroenterol. 2009;25:1228.

12. Conrad $\mathrm{M}$ and Umbreit J. Iron absorption the mucinmobilferrinintegrin pathway. A competitive pathway for metal absorption. Am J Hematol. 1993;42:67-73.

13. Kumar A, Jain S, Singh N, Singh T. Oral versus high dose parenteral iron supplementation in pregnancy. Int J Gynecol Obstet. 2005;89(1):7-13.

14. Sharma N. Iron absorption: IPC therapy is superior to conventional iron salts. Obstet Gynecol. 2001:515-9.

15. Barton JC, Barton EH, Bertoli LF, Gothard $\mathrm{CH}$, Sherrer JS. Intravenous iron dextran therapy in patients with iron deficiency and normal renal function who failed to respond to or did not tolerate oral iron supplementation. Am J Med. 2000;109(1):27-32.

16. Henry DH, Dahl NV, Auerbach M, Tchekmedyian S, Laufman LR. Intravenous ferric gluconate significantly improves response to epoetin alfa versus oral iron or no iron in anemic patients with cancer receiving chemotherapy. Oncol. 2007;12(2):231-42.

17. Auerbach M, Ballard H, Glaspy J. Clinical update: intravenous iron for anaemia. Lancet. 2007;369(9572):1502-4.

18. Rodgers GM, Auerbach M, Cella D, Chertow GM, Coyne DW, Glaspy JA, et al. High-molecular weight iron dextran: a wolf in sheep's clothing?. J American Soc Nephrol. 2008;19(5):833-4.

19. Gilreath JA, Sageser DS, Jorgenson JA, Rodgers GM. Establishing an anemia clinic for optimal erythropoietic-stimulating agent use in hematologyoncology patients. J Nat Comp Cancer Netw. 2008;6(6):577-84.

20. Mamula P, Piccoli DA, Peck SN, Markowitz JE, Baldassano RN. Total dose intravenous infusion of iron dextran for iron-deficiency anemia in children with inflammatory bowel disease. J Pediatr Gastroenterol Nutr. 2002;34(3):286-90.

21. Fletes R, Lazarus JM, Gage J, Chertow GM. Suspected iron dextran-related adverse drug events in hemodialysis patients. Am J Kidney Dis. 2001;37(4):743-9.

22. Eschbach JW, Egrie JC, Downing MR, Browne JK, Adamson JW. Correction of the anemia of end-stage renal disease with recombinant human erythropoietin. N Engl J Med. 1987;316(2):73-8.

23. Fishbane S, Ungureanu VD, Maesaka JK, Kaupke CJ, Lim V, Wish J. The safety of intravenous iron dextran in hemodialysis patients. Am J Kidney Dis. 1996;28(4):529-34.
24. Michael B, Coyne DW, Fishbane S, Folkert V, Lynn $\mathrm{R}$, Nissenson AR, et al. Sodium ferric gluconate complex in hemodialysis patients: adverse reactions compared to placebo and iron dextran. Kidney Int. 2002;61(5):1830-9.

25. Kapoian T, O'Mara NB, Singh AK, Moran J, Rizkala AR, Geronemus R, et al. Ferric gluconate reduces epoetin requirements in hemodialysis patients with elevated ferritin. J Am Soc Nephrol. 2008;19(2):3729.

26. Coyne DW, Kapoian T, Suki W, Singh AK, Moran JE, Dahl NV, et al. Ferric gluconate is highly efficacious in anemic hemodialysis patients with high serum ferritin and low transferrin saturation: results of the Dialysis Patients' Response to IV Iron with Elevated Ferritin (DRIVE) Study. J Am Soc Nephrol. 2007;18(3):975-84.

27. Aronoff GR, Bennett WM, Blumenthal S, Charytan C, Pennell JP, Reed J, et al. Iron sucrose in hemodialysis patients: safety of replacement and maintenance regimens. Kidney Int. 2004;66(3):11938.

28. Van Wyck DB, Roppolo M, Martinez CO, Mazey RM, Mcmurray S. A randomized, controlled trial comparing IV iron sucrose to oral iron in anemic patients with nondialysis-dependent CKD. Kidney Int. 2005;68(6):2846-56.

29. Macdougall IC, Roche A. Administration of intravenous iron sucrose as a 2-minute push to CKD patients: a prospective evaluation of 2,297 injections. Am J Kidney Dis. 2005;46(2):283-9.

30. Anker SD, Comin Colet J, Filippatos G, Willenheimer R, Dickstein K, Drexler H, et al. Ferric carboxymaltose in patients with heart failure and iron deficiency. New Eng J Med. 2009;361(25):2436-48.

31. Singh A, Patel T, Hertel J, Bernardo M, Kausz A, Brenner L. Safety of ferumoxytol in patients with anemia and CKD. Am J Kidney Dis. 2008;52(5):907-15.

32. Wikstrom B, Bhandari S, Barany P, Kalra PA, Ladefoged S, Wilske J. Monofer, a novel intravenous iron oligosaccharide for treatment of iron deficiency in patients with chronic kidney disease (CKD). World Congress Nephrol Milan. 2009.

Cite this article as: Saber M, Khalaf M, Abbas AM, Abdullah SA. Management of postpartum iron deficiency anemia: review of literature. Int J Reprod Contracept Obstet Gynecol 2019;8:338-42. 